\title{
SPATIOTEMPORAL VARIATIONS IN THE IMPACTS OF URBAN LAND USE TYPES ON URBAN HEAT ISLAND EFFECTS: THE CASE OF RIYADH, SAUDI ARABIA
}

\author{
Y. A. Aina ${ }^{1,2, *}$, E. M. Adam ${ }^{2}$, F. Ahmed ${ }^{2}$ \\ ${ }^{1}$ Department of Geomatics Engineering Technology, Yanbu Industrial College, Yanbu, Saudi Arabia - ainay@ rcyci.edu.sa \\ ${ }^{2}$ School of Geography, Archaeology and Environmental Studies, University of Witwatersrand, Johannesburg, South Africa - \\ elhadi.adam@wits.ac.za, fethi.ahmed@wits.ac.za
}

KEY WORDS: Landsat, Land Surface Temperature, Land Use/Land Cover, Riyadh, Urban Expansion, Urban Heat Island

\begin{abstract}
:
Urban heat island (UHI) effect is considered to be one of the key indicators of the impacts of urbanization and the climate changes on the environment. Thus, the growing interest in studying the impacts of urbanization on changes in land surface temperature (LST). The literature on LST indicates the need for more studies on the relationship between changes in LST and land use types, especially in the arid environment. This paper examines the spatial and temporal changes in land surface temperature influenced by land use/land cover types in Riyadh, Saudi Arabia. Multi-temporal Landsat images of the study area, 1985, 1995, 2002 and 2015, were processed to derive land surface temperatures. UHI index was computed for the different land use/land cover types (highdensity residential, medium-density residential, low-density residential, industrial, vegetation, and desert) in the study area. The results indicate a trend of rising temperatures in all the land use types in the study area. This is probably due to climate change. The industrial area has the highest temperatures among the land use types. The lowest temperatures are found in the vegetation area as expected. There is a need to implement mitigating measures to reduce the effects of rising temperatures in the study area.
\end{abstract}

\section{INTRODUCTION}

The level of urban growth and spatial expansion, especially in the developing countries, has been unprecedented. The global urban spatial extent has been increasing at a rate higher than urban population growth rate (Seto et al., 2011). The global urban extent that increased by $58,00 \mathrm{~km}^{2}$ from 1970 to 2000 is expected to most likely increase by 1.5 million $\mathrm{km}^{2}$ in 2030 (Seto et al., 2011). A recent study by Li et al. (in press) posited that global urban extent could increase by 1.2 million $\mathrm{km}^{2}$ from 2010 to 2050. The rapid expansion of urban land use has impacts on climate (Seto and Shepherd, 2009; Mishra et al., 2015), flood risk (Muis et al., 2015), biodiversity (Grimm et al., 2008), carbon emissions (Houghton et al., 2012) and energy use (Santamouris et al., 2015; Güneralp et al., 2017). The impacts pose challenges to cities in their drives towards achieving urban sustainability and meeting the sustainable development goals (SDG).

One of the impacts of rapid urbanization and urban expansion is urban heat island (UHI). Urban heat island is attracting growing attention due to its implication for climate change and urban sustainability. It is an occurrence whereby an urban area has a higher temperature than its surroundings (Voogt and Oke, 2003). The urban heat island effects are caused by the anthropogenic features and activities of urban areas. Urban natural surfaces are changed to impervious surfaces, buildings and road network during the process of urbanization and spatial expansion. The variations in the surface materials, land use and morphology of urban areas influence local temperatures and make urban areas warmer than the surrounding non-urbanized areas. It is important to monitor urban heat island effects to implement mitigating measures. However, the conventional way of monitoring through ground measurements is limited in spatial coverage. Historical weather data are obtained mainly from airports and weather stations that might be located on the outskirts of cities. It might not be feasible to obtain data with adequate spatial coverage through ground measurements due to the required sampling ( $\mathrm{Li}$ et al., 2013). The development of thermal remote sensing has provided opportunities for getting data at varying spatial resolution and coverage.

Satellite-derived thermal data have been used to study UHI parameters and the relationship between UHI and urban physical components (Voogt and Oke, 2003; Weng, 2009; Ngie et al., 2014). Yue et al. (2007) and Zhang et al. (2009) examined the relationship between satellite-derived land surface temperature (LST) and normalized difference vegetation index (NDVI), a measure of vegetation abundance. Studies by Zhou et al. (2011), Lu et al. (2015), Gage and Cooper (2017), Odindi et al. (2017) and Berger et al. (2017) highlighted the relationship between LST and land use/land cover. Gage and Cooper (2017) and Berger et al. (2017) included vertical structure in their analysis to study the effect of the height of structures on surface temperature. Bechtel (2012) and Jiang and Weng (2017) estimated UHI parameters from land surface temperature. Though the need for more studies on the estimation of UHI parameters had been emphasized by Weng (2003), the studies on the relationship between LST and urban land use/land cover still prevail. Time series and statistical analysis and modelling (Fu and Weng, 2016; Li et al., 2017; Tran et al., 2017) have been used to better understand the influence of the characteristics of urban surfaces on UHI.

In Saudi Arabia, particularly Riyadh, the studies on UHI are limited despite the rapid spatial expansion of the major cities (Aina et al., 2008; Rahman, 2016; Alqurashi et al., 2016a;2016b) and some documented environmental impacts

\footnotetext{
* Corresponding author
} 
(Aina et al., 2014; Alqurashi and Kumar, 2016). The studies by Lim et al. (2007) and (2011), Hereher (2016) and Aina et al. (2017) were based on Madinah, Qassim, Makkah area and Yanbu. The studies on Riyadh were based either on single year analysis or old satellite data (at least five years old) (Alghamdi and Moore, 2015; Lazzarini et al., 2015). Thus, this study aims at examining the effects of variations in land use/land cover types on urban heat island effects in Riyadh.

\section{MATERIALS AND METHODS}

\subsection{Study Area}

Riyadh is the capital of Saudi Arabia and the largest city with a global city status (Short, 2017). According to a government estimate in 2016, the population of the city is about 6.5 million and the population growth rate is about $4 \%$ (http://www.arriyadh.com/Eng). The number of housing units in Riyadh is 1.2 million (http://www.arriyadh.com/Eng). It is located close to the centre of Saudi Arabia, away from the two coasts at the west and east of the country (Figure 1). Riyadh climate is dry and the temperature varies from 11 degrees Celsius in winter to 42 degrees Celsius in summer (http://www.arriyadh.com/Eng). Though recent efforts have been made to establish public transport in Riyadh, the city's transportation has been automobile-dependent. This has implications for greenhouse gas emission and urban climate.

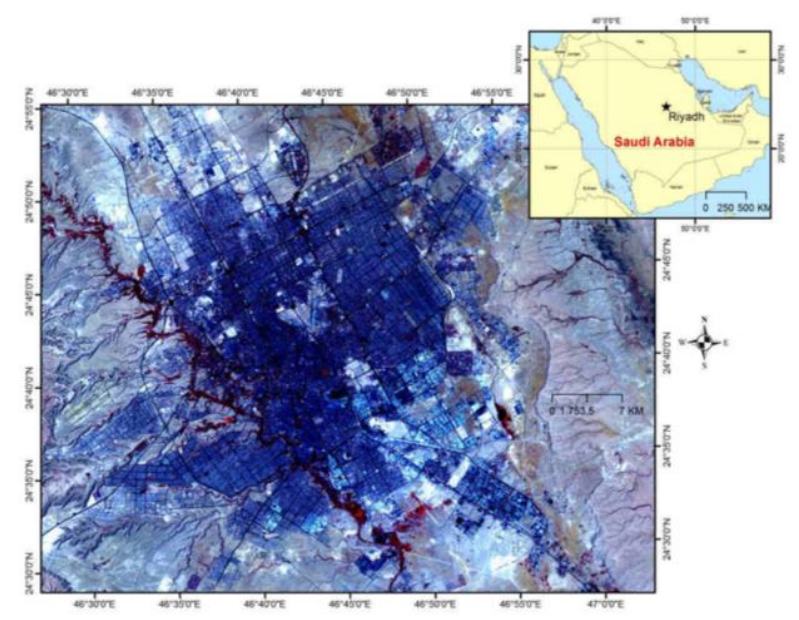

Figure 1. Location and spatial extent of Riyadh

\subsection{Landsat and urban density data acquisition}

The study used multi-temporal Landsat data downloaded from the USGS website (https://earthexplorer.usgs.gov). The years and the sensors of the data downloaded are shown below (Table 1). The study area is located at the edge of two Landsat scenes, so two images were downloaded for each year.

\begin{tabular}{|c|c|c|}
\hline Sensor & Path/Row & Date \\
\hline TM & $\begin{array}{ll}165 / 043 & 166 / 043 \\
165 / 043 & 166 / 043\end{array}$ & $\begin{array}{l}22 \text { June/31 July } 1985 \\
4 \text { July/13 Sept. } 1995\end{array}$ \\
\hline ETM+ & $165 / 043166 / 043$ & 31 July/6 July 2002 \\
\hline TIRS & $165 / 043$ 166/043 & 27 July/18 July 2015 \\
\hline
\end{tabular}

Table 1. Details of the downloaded satellite data

An urban density map of Riyadh was extracted from an official document (ADA, 2003) and Google Earth was used to confirm the density of the identified residential density areas (High,
Medium and Low). The confirmation was carried out by checking the closeness/compactness and height of the buildings. The assumption is that high-density areas will have high buildings that are close to one another while low-density areas will have low buildings that have spacious surroundings. Other land use/land cover types such as industrial, vegetation and desert were identified by using Google Earth only. Samples (50 points per land use/land cover) were taken to analyse the effect of land use land cover on UHI (a total of 300 points).

\subsection{LST estimation and data analysis}

The first step in estimating LST is to convert the pixel values of the dataset to at-sensor spectral radiance $\left(L_{\lambda}\right)$ by using Eq. 1 .

$$
\mathrm{L} \lambda=\text { Gain } * \mathrm{DN}+\text { Bias }
$$

where $\quad L_{\lambda}=$ at-sensor radiance

Gain = slope of the radiance $($ Table 2$)$

Bias $=$ intercept of the radiance $($ Table 2$)$

$\mathrm{DN}=$ digital number (pixel values)

\begin{tabular}{|l|c|c|c|}
\hline Sensor & Band & Gain & Bias \\
\hline TM & $6 \mathrm{~L}$ & 0.055158 & 1.2378 \\
\hline ETM+ & $6 \mathrm{~L}$ & 0.0 & 17.04 \\
\hline TIRS & 10 & 0.000334 & 0.10000 \\
\hline
\end{tabular}

Table 2. DN conversion coefficients (Source: Chander et al., 2009)

The second step is to compute the LST by using inverse Planck function in Eq. 2.

$$
\mathrm{LST}=\mathrm{K}_{2} / \ln \left(\mathrm{K}_{1} / L_{\lambda}+1\right)
$$

where LST $=$ LST at-satellite brightness (Ye et al., 2017)

$\mathrm{K}_{1}=$ calibration constants (Table 3 )

$\mathrm{K}_{2}=$ calibration constants (Table 3 )

$L_{\lambda}=$ at-sensor radiance from Eq. 1

\begin{tabular}{|c|c|c|}
\hline Sensor & $\mathrm{K}_{1}(\mathrm{~W} \mathrm{~m}-2 \mathrm{sr}-1 \mu \mathrm{m}-1)$ & $\mathrm{K}_{2}(\mathrm{~K})$ \\
\hline TM & 607.76 & 1260.56 \\
\hline ETM+ & 666.09 & 1282.71 \\
\hline TIRS & 774.8853 & 1321.0789 \\
\hline
\end{tabular}

Table 3. Thermal band calibration constants (Source: Chander et al., 2009)

The term calculated in Eq. 2 is the brightness temperature or atsatellite brightness. The result from the equation can still be processed further to get higher accuracy by using LST derivation algorithms and atmospheric data. Nevertheless, atsatellite brightness used to represent LST if there are no atmospheric data or the focus is on long-term trend as argued by Ye et al. (2017). Thus, LST is represented in this study by atsatellite brightness as suggested by Ye et al. (2017).

After the derivation of the LST, the sample points (300) were used to extract the LST values for the different land use/land cover types. The statistics (mean and standard deviation) of the values were computed for the different land use/land cover types. One way analysis of variance (ANOVA) was performed to determine if the differences observed in the LST values were significant. 
In addition, a UHI index was calculated for the different land use/land cover using SUHI - Surface Urban Heat Island, as shown in Eq. 3 (Voogt and Oke, 2003; Lazzarini et al., 2015).

$$
\mathrm{SUHI}=\mathrm{LST}^{(\mathrm{URB})}-\mathrm{LST}^{(\mathrm{SUB})}
$$

where $\quad \mathrm{LST}^{(\mathrm{URB})}=\mathrm{LST}$ of urban area (Land use types) $\mathrm{LST}^{(\mathrm{SUB})}=\mathrm{LST}$ of suburban area (Desert)

\section{RESULTS AND DISCUSSION}

\subsection{Satellite-derived LST}

The result of the LST from 1985 to 2015 (Figure 2) shows no prominent trend of increasing maximum temperature. However, the minimum temperature starts its increasing trend from 1995 to 2015 . The highest minimum temperature shown is $32^{\circ} \mathrm{C}$ in 2015 while the lowest temperature is $15^{\circ} \mathrm{C}$ in 1995 .
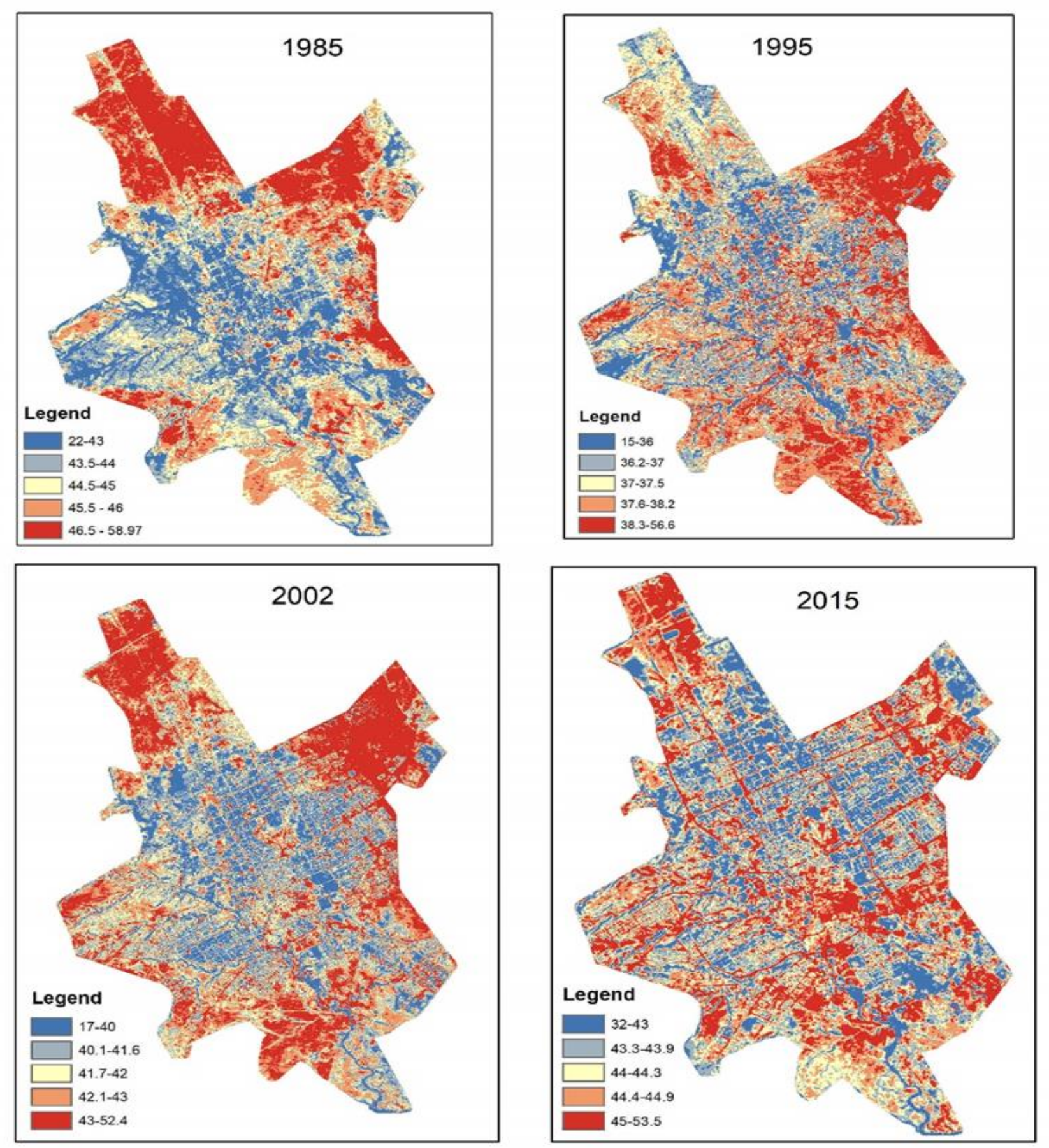

Figure 2. LST dynamics in Riyadh from 1985 to 2015 
High temperature values can be seen along the transportation network. The 2015 image (Figure 2) shows the most prominent high temperatures along transport corridors. This is most likely due to the increasing number of vehicles plying Riyadh roads.

\subsection{LST and land use types}

The results of the statistical analysis are shown below (Table 4 and 5). They show that the desert is generally warmer than the other land use/land cover types. This buttresses the findings of the previous studies by Alghamdi and Moore (2015) on Riyadh and Aina et al. (2017) on Yanbu. The LST means in 1995 are lower than the means of other years. This might probably due to an increase in the vegetation cover from 1985 to 1995 . Aina et al. (2008) and Alghamdi and Moore (2015) highlighted that the vegetation cover in Riyadh increased from 1985 to 1998 and thereafter started decreasing. However, changes in the vegetation cover of the built-up area might not account for the decrease in desert temperatures in 1995. The results indicate a trend of increasing temperatures in all the land use/land cover types from 1995 to 2015. The result of the one-way analysis of variance indicates significant differences in the LST of the land use land cover types at 0.01 level.

\begin{tabular}{|l|l|l|l|l|}
\hline \multirow{2}{*}{$\begin{array}{l}\text { Land use } \\
\text { type }\end{array}$} & \multicolumn{2}{|c|}{1985} & \multicolumn{2}{c|}{1995} \\
\cline { 2 - 5 } & Mean & $\begin{array}{l}\text { Standard } \\
\text { Deviation }\end{array}$ & Mean & $\begin{array}{l}\text { Standard } \\
\text { Deviation }\end{array}$ \\
\hline Desert & 45.58 & 3.28 & 37.84 & 1.23 \\
\hline High density & 42.34 & 0.73 & 37.36 & 1.18 \\
\hline $\begin{array}{l}\text { Medium } \\
\text { density }\end{array}$ & 45.63 & 1.83 & 37.62 & 1.07 \\
\hline Low density & 43.62 & 1.07 & 37.64 & 1.03 \\
\hline Industrial & 40.47 & 3.78 & 36.13 & 3.48 \\
\hline Vegetation & 43.33 & 4.54 & 35.25 & 3.08 \\
\hline
\end{tabular}

Table 4. Mean and standard deviation of LST by land use types in 1985 and 1995.

\begin{tabular}{|l|l|l|l|l|}
\hline \multirow{2}{*}{$\begin{array}{l}\text { Land use } \\
\text { type }\end{array}$} & \multicolumn{2}{|c|}{2002} & \multicolumn{2}{c|}{2015} \\
\cline { 2 - 5 } & Mean & $\begin{array}{l}\text { Standard } \\
\text { Deviation }\end{array}$ & Mean & $\begin{array}{l}\text { Standard } \\
\text { Deviation }\end{array}$ \\
\hline Desert & 44.15 & 1.78 & 45.22 & 1.25 \\
\hline High density & 42.05 & 0.95 & 44.39 & 0.51 \\
\hline $\begin{array}{l}\text { Medium } \\
\text { density }\end{array}$ & 42.97 & 1.76 & 43.46 & 0.67 \\
\hline Low density & 40.82 & 1.19 & 43.60 & 0.86 \\
\hline Industrial & 40.98 & 3.73 & 45.14 & 1.97 \\
\hline Vegetation & 40.19 & 4.53 & 40.30 & 2.90 \\
\hline
\end{tabular}

Table 5. Mean and standard deviation of LST by land use types in 2002 and 2015.

\subsection{SUHI analysis}

The SUHI analysis shows that the desert is warmer than the other land use/land cover types (Table 6). Almost all the SUHI results are negative except the SUHI of medium density in 1985 (Table 6). The results are in line with the findings of Alghamdi and Moore (2015) but conflicts with the findings of Lazzarini et al. (2015). Lazzarini et al. (2015) claimed that the built-up area of Riyadh has positive SUHI compared with the suburbs (the desert area). The SUHI values of high-density, low-density, and industrial areas show an increasing trend from 1985 to 2015 to indicate that their values are nearing the desert values (Table 6).
On the other hand, the SUHI values of vegetation and medium density areas show a reducing trend (Table 6).

\begin{tabular}{|l|l|l|l|l|}
\hline SUHI & 1985 & 1995 & 2002 & 2015 \\
\hline High density & -3.25 & -0.482474 & -2.10 & -0.82 \\
\hline $\begin{array}{l}\text { Medium } \\
\text { density }\end{array}$ & 0.05 & -0.21653 & -1.18 & -1.76 \\
\hline Low density & -1.96 & -0.200666 & -3.34 & -1.61 \\
\hline Industrial & -5.11 & -1.711856 & -3.18 & -0.08 \\
\hline Vegetation & -2.25 & -2.59453 & -3.97 & -4.92 \\
\hline
\end{tabular}

Table 6. SUHI values of different land use types $(1985-2015)$

\section{CONCLUSIONS}

The study has shown the changes in the LST values of the different land use types in Riyadh. The trends of some of the indices require attention. There is a need for further study to derive the LST rather than using the at-satellite brightness. Also, population data of the study area can be used to analyse the exposure of the populace to high temperatures.

Different mitigation measures should be introduced to abate the negative trends. The recent initiative to design road centrelines with greenery might be useful in reducing UHI effects in Riyadh.

\section{ACKNOWLEDGEMENTS}

The authors would like to acknowledge the assistance of the following institutions in the acquisition of the necessary data for this work - King Abdul Aziz City for Science and Technology (KACST), ArRiyadh Development Authority (ADA), and United States Geological Survey (USGS).

\section{REFERENCES}

ADA, 2003. Strategic Plan of Northern Riyadh (Arabic). ArRiyadh Development Authority (ADA), Riyadh.

Aina, Y.A., Parvez, I.M. and Balogun, A.L., 2017. Examining the Effect of Land Use on the Spatiotemporal Dynamics of Urban Temperature in an Industrial City: A Landsat Imagery Analysis. In Global Changes and Natural Disaster Management: Geo-information Technologies (pp. 3-15). Springer, Cham.

Aina, Y.A., Van der Merwe, J.H. and Alshuwaikhat, H.M., 2008. Urban spatial growth and land use change in Riyadh: Comparing spectral angle mapping and band ratioing techniques. In Proceedings of the Academic Track of the 2008 Free and Open Source Software for Geospatial (FOSS4G) Conference, incorporating the GISSA 2008 Conference, Cape Town, South Africa (pp. 51-57).

Aina, Y.A., Van der Merwe, J.H. and Alshuwaikhat, H.M., 2014. Spatial and temporal variations of satellite-derived multiyear particulate data of Saudi Arabia: An exploratory analysis. International Journal of Environmental Research and Public Health, 11(11), pp.11152-11166.

Alghamdi, A.S. and Moore, T.W., 2015. Detecting Temporal Changes in Riyadh's Urban Heat Island. Papers in Applied Geography, 1(4), pp.312-325. 
Alqurashi, A.F., Kumar, L. and Al-Ghamdi, K.A., $2016 \mathrm{a}$. Spatiotemporal modeling of urban growth predictions based on driving force factors in five Saudi Arabian cities. ISPRS International Journal of Geo-Information, 5(8), p.139.

Alqurashi, A.F., Kumar, L. and Sinha, P., 2016b. Urban land cover change modelling using time-series satellite images: A case study of urban growth in five cities of Saudi Arabia. Remote Sensing, 8(10), p.838.

Alqurashi, A.F. and Kumar, L., 2016. Spatiotemporal patterns of urban change and associated environmental impacts in five Saudi Arabian cities: A case study using remote sensing data. Habitat International, 58, pp.75-88.

Bechtel, B., 2012. Robustness of annual cycle parameters to characterize the urban thermal landscapes. IEEE Geoscience and Remote Sensing Letters, 9(5), pp.876-880.

Berger, C., Rosentreter, J., Voltersen, M., Baumgart, C., Schmullius, C. and Hese, S., 2017. Spatio-temporal analysis of the relationship between 2D/3D urban site characteristics and land surface temperature. Remote Sensing of Environment, 193, pp.225-243.

Chander, G., Markham, B.L. and Helder, D.L., 2009. Summary of current radiometric calibration coefficients for Landsat MSS, TM, ETM+, and EO-1 ALI sensors. Remote sensing of environment, 113(5), pp.893-903.

Fu, P. and Weng, Q., 2016. A time series analysis of urbanization induced land use and land cover change and its impact on land surface temperature with Landsat imagery. Remote Sensing of Environment, 175, pp.205-214.

Gage, E.A. and Cooper, D.J., 2017. Relationships between landscape pattern metrics, vertical structure and surface urban Heat Island formation in a Colorado suburb. Urban Ecosystems, pp.1-10.

Grimm, N.B., Faeth, S.H., Golubiewski, N.E., Redman, C.L., Wu, J., Bai, X. and Briggs, J.M., 2008. Global change and the ecology of cities. Science, 319(5864), pp.756-760.

Güneralp, B., Zhou, Y., Ürge-Vorsatz, D., Gupta, M., Yu, S., Patel, P.L., Fragkias, M., Li, X. and Seto, K.C., 2017. Global scenarios of urban density and its impacts on building energy use through 2050. Proceedings of the National Academy of Sciences, p.201606035.

Hereher, M.E., 2016. Recent trends of temperature and precipitation proxies in Saudi Arabia: implications for climate change. Arabian Journal of Geosciences, 9(11), p.575.

Houghton, R.A., House, J.I., Pongratz, J., Van der Werf, G.R., DeFries, R.S., Hansen, M.C., Quéré, C.L. and Ramankutty, N., 2012. Carbon emissions from land use and land-cover change. Biogeosciences, 9(12), pp.5125-5142.

Jiang, Y. and Weng, Q., 2017. Estimation of hourly and daily evapotranspiration and soil moisture using downscaled LST over various urban surfaces. GIScience \& Remote Sensing, 54(1), pp.95-117.

Lazzarini, M., Molini, A., Marpu, P.R., Ouarda, T.B. and Ghedira, H., 2015. Urban climate modifications in hot desert cities: The role of land cover, local climate, and seasonality. Geophysical Research Letters, 42(22), pp.9980-9989.

Li, X., Chen, G., Liu, X., Liang, X., Wang, S., Chen, Y., Pei, F. and $\mathrm{Xu}, \mathrm{X}$., in press. A New Global Land-Use and Land-Cover Change Product at a 1-km Resolution for 2010 to 2100 Based on Human-Environment Interactions. Annals of the American Association of Geographers. DOI: $10.1080 / 24694452.2017 .1303357$

Li, X., Kamarianakis, Y., Ouyang, Y., Turner II, B.L. and Brazel, A., 2017. On the association between land system architecture and land surface temperatures: Evidence from a Desert Metropolis-Phoenix, Arizona, USA. Landscape and Urban Planning, 163, pp.107-120.

Li, Z.L., Tang, B.H., Wu, H., Ren, H., Yan, G., Wan, Z., Trigo, I.F. and Sobrino, J.A., 2013. Satellite-derived land surface temperature: Current status and perspectives. Remote Sensing of Environment, 131, pp.14-37.

Lim, H.S., Jafri, M., Abdullah, K. and Alsultan, S., 2012. Application of a simple mono window land surface temperature algorithm from Landsat ETM over Al Qassim, Saudi Arabia. Sains Malaysiana, 41(7), pp.841-846.

Lim, H.S., MatJafri, M.Z., Abdullah, K., Saleh, N.M. and AlSultan, S., 2007. Application of Remote Sensing for Land surface temperature retrieval over Mecca. In Defense and Security Symposium (pp. 65410D-65410D). International Society for Optics and Photonics.

Lu, D., Song, K., Zang, S., Jia, M., Du, J. and Ren, C., 2015. The effect of urban expansion on urban surface temperature in Shenyang, China: an analysis with landsat imagery. Environmental Modeling \& Assessment, 20(3), pp.197-210.

Mishra, V., Ganguly, A.R., Nijssen, B. and Lettenmaier, D.P., 2015. Changes in observed climate extremes in global urban areas. Environmental Research Letters, 10(2), p.024005.

Muis, S., Güneralp, B., Jongman, B., Aerts, J.C. and Ward, P.J., 2015. Flood risk and adaptation strategies under climate change and urban expansion: A probabilistic analysis using global data. Science of the Total Environment, 538, pp.445-457.

Ngie, A., Abutaleb, K., Ahmed, F., Darwish, A. and Ahmed, M., 2014. Assessment of urban heat island using satellite remotely sensed imagery: a review. South African Geographical Journal, 96(2), pp.198-214.

Odindi, J., Mutanga, O., Abdel-Rahman, E.M., Adam, E. and Bangamwabo, V., 2017. Determination of urban land-cover types and their implication on thermal characteristics in three South African coastal metropolitans using remotely sensed data. South African Geographical Journal, 99(1), pp.52-67.

Rahman, M.T., 2016. Land use and land cover changes and urban sprawl in Riyadh, Saudi Arabia: An analysis using multitemporal Landsat data and SHANNON'S Entropy Index. ISPRS-International Archives of the Photogrammetry, Remote Sensing and Spatial Information Sciences, pp.1017-1021.

Santamouris, M., Cartalis, C., Synnefa, A. and Kolokotsa, D., 2015. On the impact of urban heat island and global warming on the power demand and electricity consumption of buildings-A review. Energy and Buildings, 98, pp.119-124. 
Seto, K.C., Fragkias, M., Güneralp, B. and Reilly, M.K., 2011. A meta-analysis of global urban land expansion. PLOS One, 6(8), p.e23777.

Seto, K.C. and Shepherd, J.M., 2009. Global urban land-use trends and climate impacts. Current Opinion in Environmental Sustainability, 1(1), pp.89-95.

Short, J.R., 2017. Global Cities. In The International Encyclopedia of Geography (pp. 1-9). John Wiley \& Sons, Ltd.

Tran, D.X., Pla, F., Latorre-Carmona, P., Myint, S.W., Caetano, M. and Kieu, H.V., 2017. Characterizing the relationship between land use land cover change and land surface temperature. ISPRS Journal of Photogrammetry and Remote Sensing, 124, pp.119-132.

Voogt, J.A. and Oke, T.R., 2003. Thermal remote sensing of urban climates. Remote sensing of environment, 86(3), pp.370384.

Weng, Q., 2009. Thermal infrared remote sensing for urban climate and environmental studies: Methods, applications, and trends. ISPRS Journal of Photogrammetry and Remote Sensing, 64(4), pp.335-344.

Ye, C., Wang, M. and Li, J., 2017. Derivation of the characteristics of the Surface Urban Heat Island in the Greater Toronto area using thermal infrared remote sensing. Remote Sensing Letters, 8(7), pp.637-646.

Yue, W., Xu, J., Tan, W. and Xu, L., 2007. The relationship between land surface temperature and NDVI with remote sensing: application to Shanghai Landsat 7 ETM+ data. International Journal of Remote Sensing, 28(15), pp.32053226.

Zhang, X., Zhong, T., Feng, X. and Wang, K., 2009. Estimation of the relationship between vegetation patches and urban land surface temperature with remote sensing. International Journal of Remote Sensing, 30(8), pp.2105-2118.

Zhou, W., Huang, G. and Cadenasso, M.L., 2011. Does spatial configuration matter? Understanding the effects of land cover pattern on land surface temperature in urban landscapes. Landscape and Urban Planning, 102(1), pp.54-63. 